\title{
Effects of Heterodera sacchari on Leaf Chlorophyll Content and Root Damage of some Upland NERICA Rice Cultivars
}

\author{
L.I. Akpheokhai ${ }^{\mathrm{a}^{*}}$, B. Fawole ${ }^{\mathrm{b}}$ and A.O. Claudius-Cole ${ }^{\mathrm{b}}$ \\ ${ }^{a}$ Department of Crop Science, Faculty of Agriculture, University of Uyo, Uyo, Nigeria. \\ ${ }^{b}$ Department of Crop Protection and Environmental Biology, Faculty of Agriculture and Forestry, University of \\ Ibadan, Ibadan.
}

\begin{abstract}
Heterodera sacchari is recognised as one of the most important soil-borne pathogens affecting rice in Nigeria. Pot and field experiments were conducted to evaluate the effect of $H$. sacchari on leaf chlorophyll content of five upland NERICA rice (NR) cultivars: NR1, NR2, NR3, NR8 and NR14. Three-week old rice plants in pots were each inoculated with: 0, 2,500, 5,000 and 10,000 eggs and juveniles, respectively. The experiment was a $5 \times 4$ factorial arranged in a complete randomised design (CRD) replicated 6 times. The field experiment was carried out on a $H$. sacchari naturally-infested field and the experimental design was a split-plot in a randomised complete block design (RCBD) replicated four times. Data were taken on leaf chlorophyll content using Minolta SPAD-502 meter. Final nematode population was determined from rice roots and soil. Root damage was accessed on a scale of $1-5$. Where: $1=(0 \%$ no damage $)$ and $5=(>75 \%$ severe root damage). Data were analyzed using ANOVA and means were separated with $L S D$ at $P \leq 0.05$. Leaf chlorophyll content of NR cultivars reduced significantly in nematode infected plants when compared with the control in both pot and field trials. Leaf chlorophyll depleted with increasing $H$. sacchari densities. In the field, leaf chlorophyll significantly reduced over time, increased root damage, wilting and eventual death of rice plants. These led to patchiness in the field, reduced plant population/ha and overall yield reduction.
\end{abstract}

Keywords: cyst nematodes, chlorophyll, yield loss, juveniles, patchiness, NERICA rice.

\section{Introduction}

Rice is an important crop in West Africa and remains essentially a grain for human consumption and a staple food for about half of the world population (Coyne et al., 2000; Nwilene et al., 2008; WARDA, 2008). It is becoming more important with demand from urban markets escalating rapidly (Randolph \& Gaye, 1996). Recent demographic growth and a dramatic increase in consumption of rice by urban populations (Adesina \& Gaye, 1993) have seen the demand for locally produced rice increase. World production is estimated at 1,843 million tonnes, which is far below the required total consumption (ERS, 2002). As a result of increase in demand, there is an urgent need to increase production, which is in turn challenged by abiotic, pest and disease problems, including nematodes.

Four species of cyst nematodes have been identified as pests of rice; Heterodera oryzicola, $\mathrm{H}$. elachista, H. oryzae and H. sacchari. H. oryzicola is found only on upland rice in Kerala State India (Bridge et al., 2005). H. oryzae occurs on lowland rice in parts of Ivory Coast and Senegal (Fortuner \& Merny, 1979), and in Bangladesh (Page \& Bridge, 1978). H. sacchari occurs on upland rice and in flooded conditions throughout West Africa (Babatola, 1984; Lamberti et al., 1991; Coyne et al., 1996; Coyne \& Plowright, 2000). H. sacchari is considered to be potentially important on rice in Nigeria (Babatola, 1983). Fademi (1984) and Coyne and Plowright (2000) reported that $H$. sacchari severely reduces rice grain yield. Fawole \& Raji (1988) observed that soils infested with $H$. sacchari may not be suitable for upland rice production. They also demonstrated that upland rice varieties infested with 50 cysts significantly reduced dry shoot and root weights and caused poor tillering. Coyne and Plowright (1998) reported yield losses due to H. sacchari by up to $50 \%$. The nematode generally attacks plants by penetrating through the root tips, migrates into the cortical cells, into the vascular elements where it establishes a permanent feeding site for its nourishment, development and multiplication. The root systems of infested plant degenerate as the nematode penetrates deeper and the infected root become necrotic, blackened and twiggy (Fademi, 1984; Babatola, 1983). As a result of damage to rice roots due to $H$. sacchari, the root efficiency is reduced and upward movement of water and inorganic substances are disrupted. Consequently, the process of photosynthesis is hampered. However, leaf chlorophyll content is essential for the process of photosynthesis and hence the resultant yield. This report elucidates the effect of $H$. sacchari on rice roots and leaf chlorophyll content of five NERICA rice cultivars in Nigeria.

\section{Materials And Methods}

Soil sterilization: Sandy-loam topsoil collected from the International Institute of Tropical Agriculture (IITA), Ibadan were sterilized for two hours thirty minutes at the temperature of $90^{\circ} \mathrm{C}$ using the soil sterilizer at the 
Nematology Laboratory, International Institute of Tropical Agriculture (IITA), Ibadan. The soil was allowed to cool for 24 hours and later transferred into 5 litres plastic pots and kept in the screen house until needed.

Sources and cultivars of seeds: Five cultivars of upland rice seeds selected on the basis of wide cultivation across Nigeria and ability to support $H$. sacchari reproduction were obtained from Africa Rice Centre (ARC) formerly known as West African Rice Development Association (WARDA), Ibadan. These included cultivars of upland New Rice for Africa (NERICA); NERICA 1, NERICA 2, NERICA 3, NERICA 8 and NERICA 14 susceptible to H. sacchari (Akpheokhai et al., 2014).

Source and extraction of cyst nematode: The cyst nematode (Fig. 1) population was obtained from experimental rice plots of Africa Rice Centre (ARC), Ikenne (Lat. $2^{0} 67^{\prime} \mathrm{N}$ and $7^{0} 97^{\prime} \mathrm{N}$, Long. $6^{0} 32^{\prime} \mathrm{E}$, and $4^{0}$ $40^{\prime} \mathrm{E}$ ), Ogun State in Nigeria. The cyst nematode culture was initiated from single cyst and multiplied on susceptible rice cultivar OS6 (Salawu, 1992) for twelve weeks for the experiment in the screenhouse, Nematology Laboratory, International Institute of Tropical Agricultre (IITA), Ibadan. Cysts were picked from infected OS6 rice roots and identified as Heterodera sacchari at Biosystematics, ARC-PPRI, Pretoria, Republic of South Africa.

Mature cysts of $H$. sacchari were collected from OS6 rice soil by floating organic debris, extracted from soil using a jet of water. This was decanted to a $250 \mu \mathrm{m}$ aperture sieve and collected in fluted filter papers. Cysts were picked with a pair of forceps from the debris into distilled water in a $200 \mathrm{ml}$ glass beaker. Cysts were individually pierced and crushed using a dissecting needle while viewing under a dissecting microscope. Broken cyst was washed into a $500 \mathrm{ml}$ beaker and the suspension agitated for five minutes to free eggs and juveniles. The liberated eggs and juveniles were subsequently collected on a stack of sieves of $60 \mu \mathrm{m}, 38 \mu \mathrm{m}$ and $25 \mu \mathrm{m}$. Where aperture size $60 \mu \mathrm{m}$ trapped the cyst cuticle, $38 \mu \mathrm{m}$ and $25 \mu \mathrm{m}$ trapped the emerging juveniles and eggs, respectively (Coyne, 1999). The eggs in distilled water were kept for 48 hours to hatch into second-stage juveniles (J2) in an incubator set at $27 \pm 0.5^{\circ} \mathrm{C}$. The $\mathrm{J} 2$ suspension was adjusted to a concentration of $1,000 \mathrm{~J} 2 \mathrm{per}$ $\mathrm{ml}$ of distilled water.

Pot trial: A pot trial was carried out in the screen house at IITA, Ibadan (Lat. $7^{\circ} 3^{\prime} \mathrm{N}, 3^{\circ} 45^{\prime} \mathrm{E}$ ). Two seeds of each of the NERICA rice cultivars previously listed above were planted in a plastic pot containing 5 litres of steam- sterilized sandy loam soil. Two weeks after planting, rice seedlings were thinned down to one stand per pot. Three weeks after sowing, seedlings were inoculated at four inoculum densities: 0 (which served as control), 2,500, 5,000 or 10,000 eggs and second-stage (J2)/plant $(0,0.5,1$ or 2 nematodes $/ \mathrm{ml}$ of soil). This was accomplished by pipeting $0,1,2$ or $4 \mathrm{ml}$ of $H$. sacchari egg and juvenile suspension respectively into four holes each $4 \mathrm{~cm}$ deep made at the base of the plants. Distilled water was introduced into the holes for 0 eggs (control). After inoculation, the holes were covered with sterilized sandy-loam soil. Each treatment was replicated six times for each cultivar. The experiment was a $5 \times 4$ factorial, (five cultivars of NERICA rice and four levels of H. sacchari inoculum) arranged in a complete randomized design (CRD) replicated six times. After inoculation, data was taken on the leaf chlorophyll content from the flag leaf of each plant using a MINOLTA 502 SPAD meter. Subsequently, this data was taken fortnightly until eleventh-week after which the experiment was terminated. The plants were adequately watered throughout the period of the study. At harvest, data were taken on root damage, fresh root weight $(\mathrm{g})$ and soil and root nematode population. Plant in each pot was carefully upturned and adhering soil particles were gently removed. The root mass from each pot was separated from the soil carefully and thereafter rinsed with tap water in a 10 litres plastic bucket to observe for nematode root damage on a scale of $1-5$ as described by Coyne et al. (2007), where; $1=$ (no damage), $2=(1-25 \%$ slight damage), $3=(26-50 \%$ mild damage $), 4=(51-74 \%$ moderate root damage $)$ and $5=(>75 \%$ severe root damage $)$. The adhering white females on roots were gently dislodged with a jet of tap water into a 10 litres plastic bucket and collected over nested sieves: $2 \mathrm{~mm}$ to trap debris, $250 \mu \mathrm{m}$ and $150 \mu \mathrm{m}$ to collect the white females as previously described in the pot experiment (Coyne et al., 2007). The extracted white females from each rice root were put together in a $250 \mathrm{ml}$ beaker for estimation using a dissecting microscope. Five grams $(5 \mathrm{~g})$ root subsample was weighed, and observed under a dissecting microscope in order to check for any adhering white females or cysts on root before the extraction second-stage juvenile extraction. Subsequently, roots were weighed using a METTLER PJ 3600 DeltaRange ${ }^{\circledR}$ balance. Soil from each pot was thoroughly mixed and 250 $\mathrm{ml}$ sub-sample was measured and air dried for cysts extraction (Coyne et al., 2007), another $250 \mathrm{ml}$ of soil subsample was measured for second-stage juvenile extraction, while roots were cut into 1-2 cm pieces and mixed thoroughly prior the extraction of second-stage using the modified Baermann extraction technique as described by Hooper (1986) where extraction trays were set up by placing a plastic sieve on a collection tray. Facial tissue spread into the plastic sieve and $250 \mathrm{ml}$ soil or roots from each plant were poured gently on the facial tissue in the sieve, thereafter, $250 \mathrm{ml}$ of distilled water was added into the collection tray. The whole extraction set up was left for 48 hours prior estimation. The juvenile population from root or soil were estimated by counting nematode from $1 \mathrm{ml}$ aliquot of the nematode suspension under the dissecting microscope.

Field trial: A piece of land naturally infested with $H$. sacchari at International Institute of Tropical Agriculture (IITA) sub-station, Ikenne, Ogun State (average annual rainfall of $1480 \mathrm{~mm}$, monthly mean temperature range of 
$18-24^{\circ} \mathrm{C}$ and soil type: Ultisol) was used for this study. In order to maintain the population of $H$. sacchari on the field, a susceptible rice cultivar, OS6, was planted on half of the land required to be used as nematode infested plot, eight weeks before the commencement of the experiment. Four beds, each $15 \mathrm{~m}$ long and $0.5 \mathrm{~m}$ wide, with a spacing of $0.5 \mathrm{~m}$ in between beds were used for the study. Each bed was then divided into two, each having a length of $7.5 \mathrm{~m}$ which gave rise to 8 beds. Four beds served as control (i.e. nematode-free) while the other four served as nematode-infested plot. After this, the control plot was denematized with carbofuran at $3 \mathrm{~kg}$ ai/ha while the nematode-infested plot was not denematized. Each bed was further subdivided into five equal subplots. Two hundred and fifty milliliters $(250 \mathrm{ml})$ of soil was then collected from each sub-plot for the extraction in order to determine the initial population $\left(\mathrm{P}_{\mathrm{i}}\right)$ of second stage juveniles $(\mathrm{J} 2)$ and cysts of $H$. sacchari prior to planting. The modified Baermann extraction technique described by Hooper (1986) was used for J2 extraction from soil and cysts extraction from soil was carried out by the technique described by Coyne et al. (2007). Cysts and J2 population were estimated by counting under the stereomicroscope or compound microscope, respectively. The five NERICA rice cultivars that were found to support $H$. sacchari reproduction namely NERICA1, 2, 3, 8 and 14 were used for this experiment. Ten seeds of each cultivar were randomly planted in each plot, such that each main-plot had the five rice cultivars planted to it at the spacing of $0.25 \mathrm{~m} \times 0.2 \mathrm{~m}$, thus a cultivar of NERICA rice was planted in each sub-plot. The experiment was a split-plot, arranged in a randomized complete block design (RCBD) with four replications. The experiment was carried out in the cropping seasons of 2011 and 2012. Plant leaf chlorophyll was collected at four weeks after planting with a MINOLTA 502 SPAD meter, and subsequently fortnightly until the twelfth week when the experiment was terminated. At harvest, data were collected on fresh root weight, root damage, and nematode reproduction as previously described in the pot experiment. Rice plants were carefully uprooted from each sub-plot with the aid of a hand trowel; the root from each plant was carefully separated from the soil by gently rinsing with tap water and thereafter observed for nematode root damage on a scale of 1-5 as described by Coyne et al. (2007). Second-stage juvenile population was also determined from roots and from $250 \mathrm{ml}$ of soil respectively as described previously in the pot experiment. Cysts and white females were also extracted and their population determined as previously described in the pot experiment. These experiments were repeated without any modifications in order to validate data.

Statistical analysis: Data were statistically analyzed using the Statistical Analysis Systems SAS 9.1 (SAS, 2002) and count data were transformed using $\log _{10}(X+1)$ before analysis (Gomez and Gomez, 1984). Means were partitioned using the Least Significant Difference (LSD) at a probability level of $5 \%$. The means of the data collected in the two trials were not significantly different $(\mathrm{P} \leq 0.05)$. Therefore, the data were combined for analysis and their means presented in both pot and field experiments.

\section{Results}

Pot trial: There was no significant difference $(\mathrm{P} \leq 0.05)$ in the leaf chlorophyll content of the control and the inoculated plants up to fourth week after inoculation (Fig. 2). However, at eight weeks after inoculation, leaf chlorophyll reduced significantly $(\mathrm{P} \leq 0.05)$ in the inoculated plants when compared with the control which had the highest mean chlorophyll content of 33.9 (Fig. 2). This was the trend up to week eleven where the inoculated NERICA rice plants had mean values of 18.9, 18.1 and 17.6 leaf chlorophyll at different inoculation level of 2,500. 5,000 and 10,000 eggs and juveniles in that order (Fig. 2). The leaf chlorophyll content of uninoculated NERICA rice cultivars were significantly higher $(\mathrm{P} \leq 0.05)$ when compared with rice plants inoculated at various nematode densities. Furthermore, leaf chlorophyll content decreases rapidly with increasing $H$. sacchari inoculum densities (Fig. 3). The fresh root weight of uninoculated NERICA rice cultivars were significantly higher $(\mathrm{P} \leq 0.05)$ than the NERICA rice inoculated at 2,500, 5,000, 10,000 eggs and second-stage juvenile $\left(\mathrm{J}_{2}\right)$ of $H$. sacchari respectively (Fig. 4). Similarly, the root damage of inoculated NERICA rice cultivars was significantly higher than the control (Fig. 5). The mean root damage of plants inoculated at 2,500, 5,000, 10,000 eggs and $\mathrm{J} 2$ of $H$. sacchari had values which ranged from $3.7-4.7$ root damage score which were not significantly different from one another (Fig. 5). Furthermore, there was severe reduction in leaf chlorophyll and fresh root weight with increasing nematode population density across NERICA rice cultivars. Similarly, the number of total second- stage juvenile (J2) in pots of plants inoculated with 5,000 and 10,000 eggs and J2 were significantly higher $(\mathrm{P} \leq 0.05)$ than pots of plants infected with nematode density of 2,500eggs and juveniles and the uninfected plants. The highest juvenile density was recorded in NERICA $2(35,925.0)$ at the inoculation density of 10,000 eggs of $H$. sacchari whereas the least was recorded in NERICA 3 (7605.0) at the inoculum density of 2,500 eggs and the controls $0.0 \mathrm{~J} 2$ (Table 1). Total cysts produced in infected plants were significantly different $(\mathrm{P} \leq 0.05)$ from uninfected plants as shown across all cultivars (Table 1). The highest number of cysts were recovered from NERICA14 plants (13,638.3 cysts) followed by NERICA1 $(13,241.3$ cysts) infected with 10,000 eggs of $\mathrm{H}$. sacchari while the least total number of cysts was recovered from NERICA 2 plants (3,215.0 cysts) inoculated with 10,000 eggs and J2 (Table 1). Furthermore, total cysts in pot 
increased with increasing inoculum densities across all cultivars also, number of eggs and juveniles per cysts ranged from 118.5 nematodes to 318.5 nematodes in all infected plants across cultivars (Table 1).

Field: In the field, leaf chlorophyll content of rice plants on the carbofuran treated field increased significantly $(\mathrm{P} \leq 0.05)$ at week 4 after planting when compared with rice plants grown on the nematode infested field (Fig. 6). This trend continued until the end of the experiment when chlorophyll content of rice plants on the treated field was 41.6 while on the untreated field, leaf chlorophyll content was 30.9 (Fig. 6). The mean leaf chlorophyll content of NERICA rice (1, 2, 3, 8 and 14) was significantly higher in the treated field than those planted in the untreated field (Fig. 7). The highest leaf chlorophyll content was recorded on NERICA 14 (37.7 leaf chlorophyll) planted in the treated field while the least was recorded for NERICA 2 (8.8 leaf chlorophyll) grown in the untreated field (Fig. 7). The average fresh root weight of NERICA rice cultivars grown in the control plots differ significantly from those grown in the nematode-infested plots (Fig. 8). Similarly, average root damage was significantly higher $(\mathrm{P} \leq 0.05)$ in rice planted on the nematode-infested field than those planted on the control (Fig. 9). Root damage ranged from 3.3 (NERICA8) to 3.8 (NERICA1) in the nematode-infested field. However, in the control plot, root damage ranged from 1.5 root damage (NERICA2 and NERICA14) to 2.1 root damage (NERICA8) (Fig. 9). The J2 population recovered from $250 \mathrm{ml}$ of soil and roots obtained from NERICA rice cultivars were significantly higher $(\mathrm{P} \leq 0.05)$ in rice plants grown in the nematode-infested field than those plants grown in the control across all cultivars (Table 2). However, Total J2 population of NERICA rice grown in the nematode-infested ranged from $1575.0 \mathrm{~J} 2$ (NERICA8) to $3750.0 \mathrm{~J} 2$ (NERICA1) whereas, the total $\mathrm{J}_{2}$ population in recovered from NERICA rice grown in the control field ranged from $725.0 \mathrm{~J} 2$ (NERICA8) to $1425.0 \mathrm{~J} 2$ (NERICA3) (Table 2). Similarly, the number of cysts recovered from $250 \mathrm{ml}$ soil and total cysts on root of NERICA rice cultivars grown in the nematode-infested field were significantly higher $(\mathrm{P} \leq 0.05)$ than rice plants grown in the control field (Table 2). Higher numbers of cysts were recovered from the nematode-infested field across all cultivars (Table 2). The number of cysts recovered from the NERICA rice grown in control plot ranged from 150.0 cysts (NERICA1) to 500.0 cysts (NERICA14) whereas, in the nematode-infested field, number of cysts on root ranged from 225.0 to 1000.0 cysts (Table 2). Furthermore, there were no significant differences in the mean number of nematodes recovered per cyst obtained from NERICA rice cultivars grown in both nematode-infested field and those obtained from the control field, although, the numerical values of number of nematode per cyst was higher in the cysts recovered from nematode-infested field than those obtained from the control (Table 2).

\section{Discussion}

The results of this investigation indicated that the pathogenic effect of cyst nematode (H. sacchari) on leaf chlorophyll content and root damage of upland NERICA rice increased with increasing nematode population densities in both pot and field trials. This can be attributed to the activities of the nematode such as penetration, migration, development and reproduction in the roots of the infected rice plants. The root systems of infected plants become necrotic, dark brown and twiggy. Furthermore, leaf chlorophyll content of infected plants reduced by $50.4 \%$ at the inoculum level of 10,000 eggs and $\mathrm{J} 2$ of $\mathrm{H}$. sacchari in pot and $60.3 \%$ in the field at the end experiment. This result is similar to Coyne and Plowright (2000) who reported 54.8\% reduction in leaf chlorophyll content in rice cultivar IDSA6 sown in sandy soil inoculated with 400 cysts per plant. They also reported that $H$. sacchari is clearly highly pathogenic on susceptible upland rice in sandy soil, very low initial population densities resulted in severe chlorosis, reduced vigour and root damage. Similarly, Babatola (1983) reported that rice plants infected with increasing inoculum H. sacchari density $(0,100,200$ and 400 cysts) led to very chlorotic condition with retarded growth in rice plants in a potted experiment. Furthermore, between 6th and 8th week after inoculation there was a sharp drop in the leaf chlorophyll content this could be attributed to the fact that the nematode may have completed at least two generations which led to increased nematode pressure on the root system of NERICA rice. The nematode activity within the root system reduces the ability of the plant to absorb water and nutrients (such as magnesium and nitrogen which are very essential in the formation of chlorophyll in plants) and this in turn results to wilting and the eventual death of some NERICA rice plants. This has direct implication on the yield since the leaf chlorophyll content has direct effect on the photosynthetic rate and crop yield. This is similar to the findings of Oyetunji et al. (2012) they reported that leaf chlorophyll content of NERICA1, OS6 and LAC 23 were significantly reduced in presence of Termite, Trichoderma sp. and Botryodiplodia theobromae in various combinations of the organisms. Agrios (2005) explained that carbon dioxide from the atmosphere and water from the soil are brought together in the chloroplasts of the green parts of plants in the presence of light to produce energy. The extensive destruction of roots by $H$. sacchari interfares with the normal absorption of water and nutrients by the root. Furthermore, high $H$. sacchari density increases metabolic activities of the roots with increased mobilization and accumulation of photosynthates from the shoot to the syncytium but these do not add to the weight of the root because nematodes feed on them. Also because of reduction in photosynthesis, enough photosynthates would not be sent down for root growth. It is also observed in this study that the number of white females and cyst produced increased with 
increase in inoculum density. This result is similar to the findings of Babatola (1983); Reversat \& Destombes (1998); Plowright et al. (1999); Audebert et al. (2000) reported that number of nematodes increased exponentially with increase in initial population levels of Heterodera spp. on rice. Salawu (1986) also reported a steady increase of $H$. sacchari white females and cyst recovered from both soil and root as inoculum density increased on both local and exotic sugarcane varieties. Generally, inoculated NERICA rice cultivars suffered in terms of root damage and poor leaf chlorophyll content compared with the uninfected NERICA rice plants. This confirms the high damage potential of $H$. sacchari on NERICA rice since cyst production is a measure of root damage. The higher the initial nematode population, the higher the level of damage imposed on infected plants. Total cysts produced in this study increased with increasing inoculum level from 2,500 to 10,000 eggs and juveniles per plant. Similar results were reported by Babatola (1983) and Salawu (1986) who observed maximum cysts as the initial inoculum density increased. The cyst produced by $H$. sacchari at inoculation density of $9,18,36$ and 72cysts per litre of soil in rice CV Faro 11 were 636, 722, 992 and 1,818 cysts per 200 $\mathrm{ml}$ soil respectively and in Sugarcane CV LS1-033 inoculated with 2,000, 4,000, 8,000 and 16,000 second stage juvenile per 5 litre of soil, number of cysts recovered from 250ml soil were 192, 256, 245 and 407 cysts respectively.

The ability of $H$. sacchari to suppress chlorophyll content of NERICA rice grown under controlled and field conditions emphasizes the potential importance of the nematode on the crop. The nematicide carbofuran used in the control plots however reduced the pre-plant nematode population, therefore the rice roots developed vigorously and subsequently promoting high chlorophyll content in plants. However, as the efficacy of the nematicide reduces over time in the field, the eggs and juveniles protected within cysts hatched out for infection of rice roots. This explains why there was increase in cysts and second-stage juveniles of $H$. sacchari recovered from the nematicide treated plots. This is an indication that the use of carbofuran does not absolutely control the cyst nematode, H. sacchari. Coyne \& Plowright (2000) demonstrated how delayed hatching of $H$. sacchari cysts makes the nematode to perpetuate and increase in population when condition becomes favorable, availability of food and preferred host. The information obtained in this study may prove useful in predicting the effect of different inoculum densities on the leaf chlorophyll content and yield of NERICA rice. At inoculum density of 2,500 eggs and juveniles per pot and above (ie $>1 \mathrm{egg} / 2 \mathrm{ml}$ soil) NERICA rice growth and development were reduced. This observation is in line with Coyne \& Plowright (2000) who reported that initial population of $H$. sacchari at 2 eggs per $\mathrm{ml}$ of soil was aggressive in the early stage of rice cultivar IDSA6.

A robust nematode management programme is therefore essential to reduce pre-plant nematode population in an infested soil as its high potential fecundity will permit population densities to reach an economic threshold and lead to damage and also considering the difficulty in controlling this nematode.

\section{Acknowledgements}

The senior author is grateful to Dr. Danny L. Coyne for offering him the use of the Nematology Research Laboratory, IITA, Ibadan, and Dr. Francis Nwilene of Africa Rice for offering him the use of his research field at Ikenne and the NERICA seeds used for the work.

\section{References}

[1]. Adesina AA, Gaye M, 1993. Rice trends in Sub-Sahara Africa: a synthesis of statistics on rice production, trade and consumption. Bouké, Côte d'Ivoire: West Africa Rice Development Association.

[2]. Agrios GN, 2005. Parasitism and Disease Development. In: Plant Pathology, Fifth edition Elsevier academic press, UK, p. 901

[3]. Akpheokhai LI, Claudius-Cole AO, Fawole B, Tanimola AA, 2014. Screening for resistance to Heterodera sacchari infection in upland rice cultivars. JNKVV Res J 48(1), 36-42

[4]. Audebert A., Coyne DL, Dingkuhn M, Plowright RA, 2000. The Influence of Cyst Nematodes (Heterodera sacchari) and Drought on Water Relations and Growth of Upland Rice in Côte d' Ivoire.

[5]. Babatola JO, 1983. Pathogenicity of Heterodera sacchari on rice. Nematologia Meditterranea 11, 21-25.

[6]. Babatola JO, 1984. Rice Nematode Problems in Nigera; their occurrence, distribution and pathogenesis. Tropical Pest Management 30, 256-265.

[7]. Bridge J, Plowright RA, Peng D, 2005. Nematode Parasite of Rice. In Luc, M., Sikora, R.A. and Bridge J, eds. Plant Parasitic Nematodes in Subtropical and Tropical Agriculture. Wallingford, U.K: CAB International, 87-130.

[8]. Coyne DL, 1999. Epidemiology and crop loss assessment of rice nematodes in West Africa. Dept. of Crop of Agriculture, University of Readings, United Kingdom, Ph.D Thesis.

[9]. Coyne DL, Plowright RA, 1998. Use of solarisation to control Heterodera sacchari and other plant parasitic nematodes in the field: a modified technique for experimental purposes. International Journal of Nematology 6, 70-73.

[10]. Coyne DL, Plowright RA, 2000. Pathogenicity of Cyst Nematode, Heterodera sacchari, on Rice in sand and Clay Soil. International Rice Research Notes (IRRN), 25: 1

[11]. Coyne DL, Hunt DJ, Plowright RA, Darboe MLK, 2000. Further observations on nematodes associated with rice in Côte d' Ivoire, The Gambia, Guinea and Togo. International Journal of Nematology: Vol. 2(10), 123-130.

[12]. Coyne DL, Nicol JM, Claudius-Cole B, 2007. Practical plant nematology: A field and laboratory guide. SP-IPM Secretariat, International Institute of Tropical Agriculture (IITA), Cotonou, Benin, p. 42-47.

[13]. Coyne DL, Plowright RA, Fofana I, 1996. Preliminary investigations of nematodes associated with rice in Guinea, Benin and Togo. Afro-Asian Journal of Nematology 6, 70-73. 
[14]. Economic Research Service (ERS), 2002. World supply and utilisation of major crops, livestocks and products. Agricultural outlook, Jan-Feb 2002/ AGO-288. Economic Research Service, US. Department of Agriculture, p. 47.

[15]. Fademi OA, 1984. Influence of rate and time of carbofuran application to control root-knot nematodes in upland rice. International Rice Research Newsletter 9 (6), 22-23.

[16]. Fawole B, Raji MA, 1988. Relationship between numbers of H. sacchari cysts and upland rice growth and development. Test of Agrochemicals and Cultivars 9, Ann. Appl. Biol. Supplement, 112:108-109.

[17]. Fortuner R, Merny G, 1979. Root-parasitic nematodes of rice. Revue de Nématologie 2, 79-102.

[18]. Gomez KA, Gomez AA, 1984. Statistical procedures for Agricultural research. Second edition. New York, NY, USA, John Wiley and Sons Inc., p. 680.

[19]. Hooper D J, 1986. Extraction of free living stages from soil. In Laboratory methods for work with plant and soil nematodes, eds. J. F. Southey Reference Book 402, Ministry of Agriculture, Fisheries and Food. London. Her Majesty's Stationary Office, London, 530 .

[20]. Lamberti F, Ciancio A, Tuopay DK, Boiboi JB, Vovlas N, Bleve-Zacheo T, Elias F, 1991. Nematode threats to rice in Liberia. Nematologia Mediterranea 19, 291-303.

[21]. Nwilene FE, Agunbiade TA,Togola MA, Youm O, Ajayi O, Oikeh SO, Ofodile S, Falola OO, 2008. Efficacy of traditional practices and botanicals for the control of termites on rice at Ikenne, Southwest Nigeria. Int. J. Trop. Insect Sci. 28 (1), $37-44$.

[22]. Oyetunji OE, Peluola OC, Nwilene FE, Akinwale G, Togola A, Agunbiade TA, Claudius-Cole AO, 2012. Effect of fungi-termite interaction on the chlorophyll content of three rice varieties grown on ultisol soil of Ikenne, southwest Nigeria. Archives of Phytopathology and Plant Protection, DOI:10.1080/03235408.2012.673263.

[23]. Page SLJ, Bridge J, 1978. Plant Nematodes on Deep Water Rice in Bangladesh. Report on Visit to Bangladesh. Ministry of Overseas Development, London, UK. Overseas Development Administration, p.48.

[24]. Plowright RA, Coyne DL, Nash P, Jones MP, 1999. Resistance to the rice nematodes Heterodera sacchari, Meloidogyne gramicola and M. incognita in Oryza glaberrima and $O$. glaberrima x $O$. sativa interspecific hybrids. Nematology $1,745-751$.

[25]. Randolph TF, Guei M, 1996. Rice trends in Sub-Saharan Africa: a synthesis of statistics on rice production, trade and consumption. Bouake (Cote d'Ivoire): West Africa Rice Development Association, p.10.

[26]. Reversat G, Destombes D, 1998. Screening for resistance to Heterodera sacchari in the two cultivated rice species, $O$. sativa and $O$. glaberrima. Fundamental and Applied Nematology 21, 307-317.

[27]. Salawu EO, 1986. The biology and host parasite relations of the sugarcane cyst nematode, Heterodera sacchari., University of Ibadan, Ph.D. thesis, 107.

[28]. SAS Institute, 2002. SAS User's Guide: Statistics, version 9.1e SAS Institute, Cary. NC. USA.

[29]. WARDA, 2008. Africa Rice Trends 2007. Cotonou, Benin: Africa Rice Center (WARDA). Fifth edition, eds. Aliou Diagne, Ibrahima Bamba, Ali A Touré, Achille Medagbe, p. 84

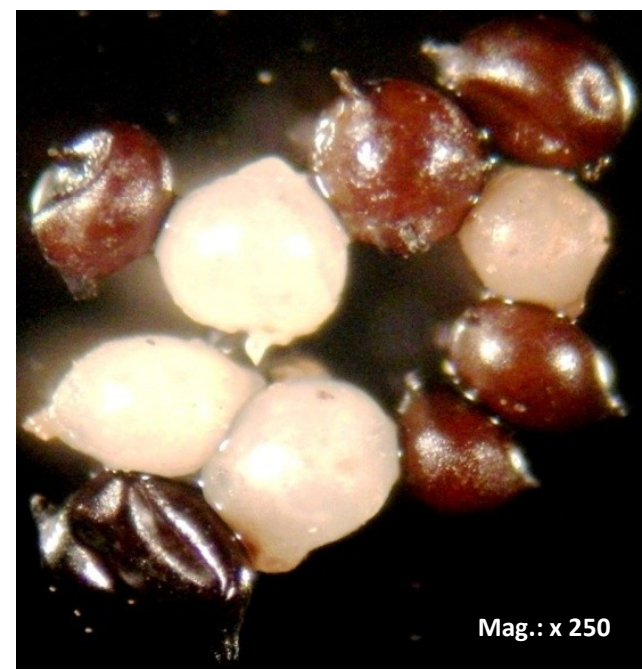

Figure 1: Brown cysts and white females of Heterodera sacchari collected from and infested rice field

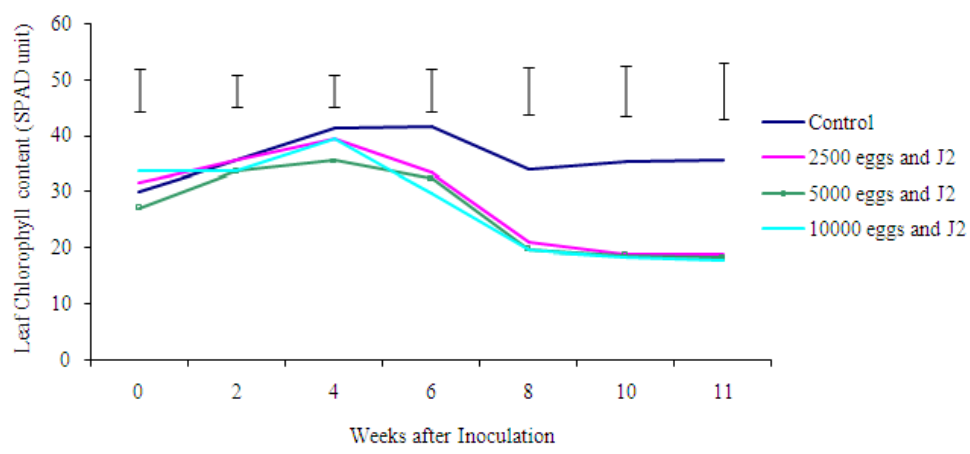

Figure 2: Effect of Heterodera sacchari population densities on leaf chlorophyll of five NERICA rice cultivars. LSD bars is for comparing treatment means at each specific time 


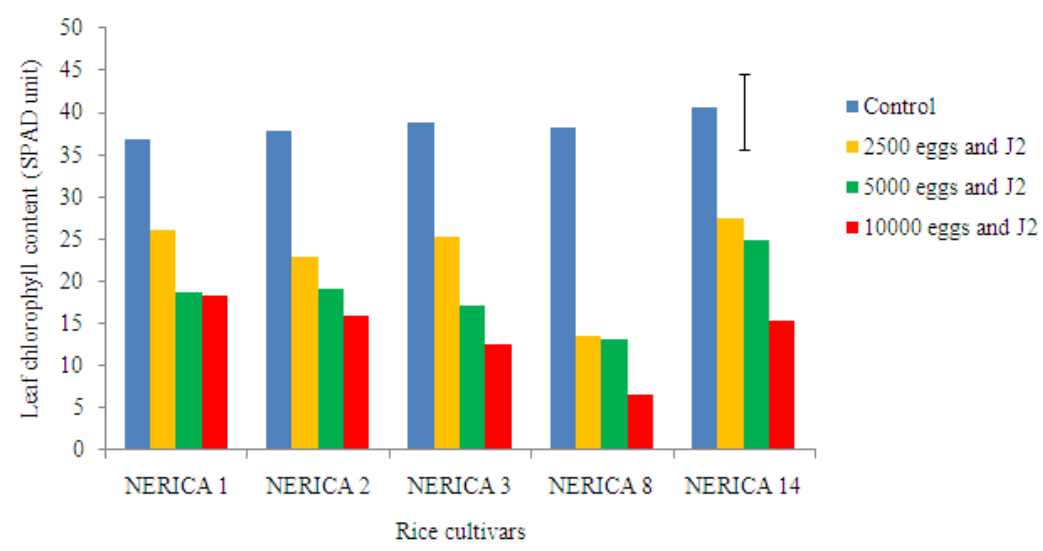

Figure 3: Effect of Heterodera sacchari population densities on leaf chlorophyll of five NERICA rice cultivars. $L S D D_{(P \leq 0.05)}$ bar is for comparing treatment means across cultivars

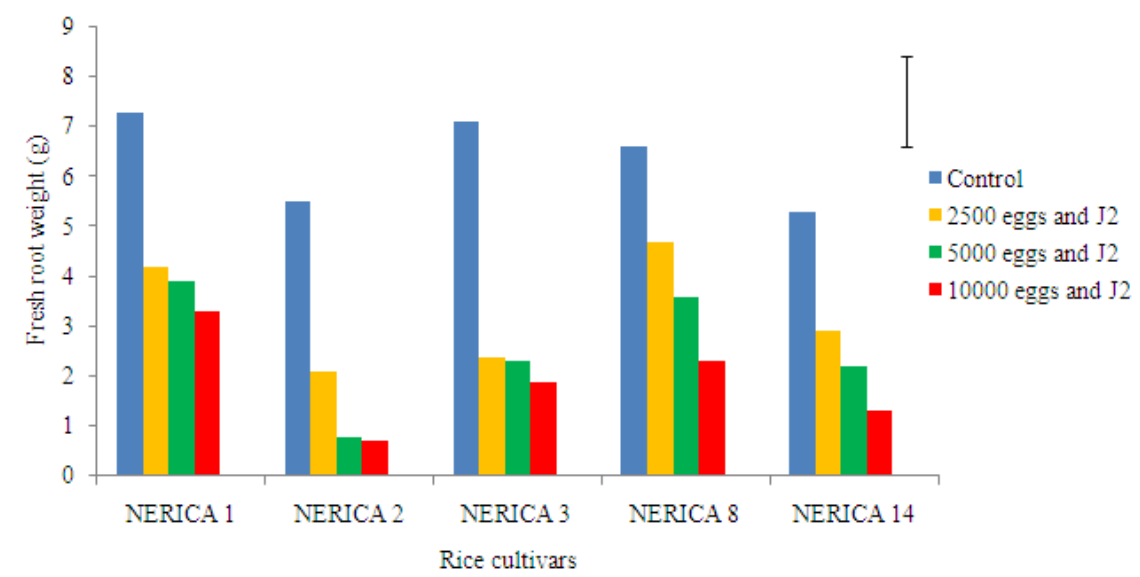

Figure 4: Effect of Heterodera sacchari population densities on fresh root weight of some NERICA rice cultivars. LSD $(\mathrm{P} \leq 0.05)$ bars for comparing treatment means across cultivars

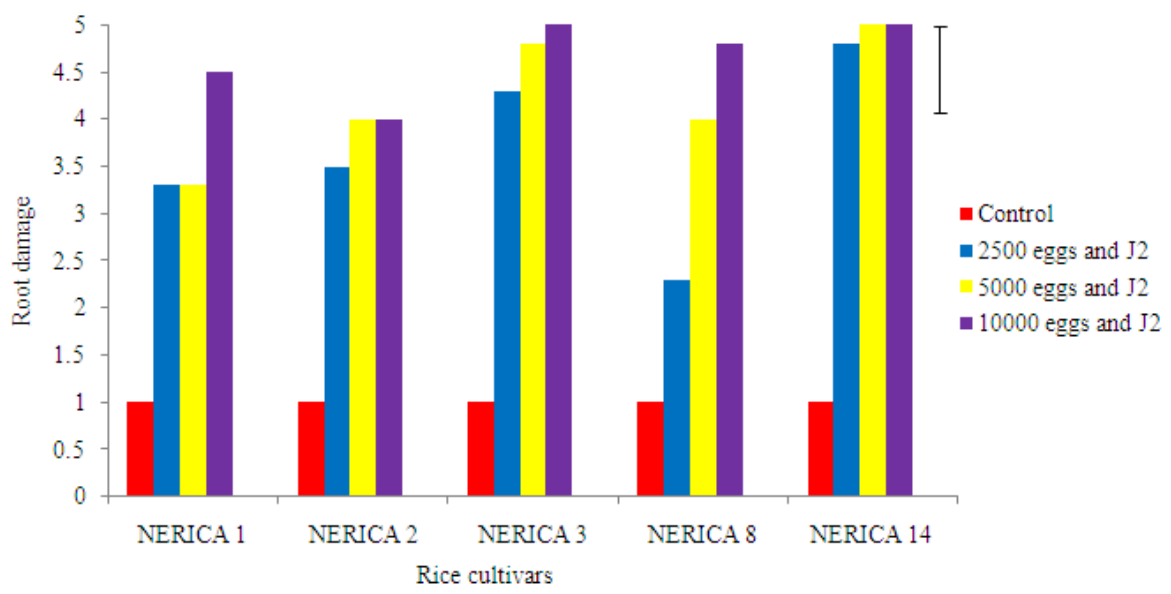

Figure 5: Effect of Heterodera sacchari population densities on root damage of some NERICA rice cultivars. LSD $(\mathrm{P} \leq 0.05)$ bars for comparing treatment means across cultivars. Root damage where; $1=$ clean, $2=(1-25 \%$ slight damage $), 3=(26-50 \%$ mild damage $), 4=(51-74 \%$ moderate root damage $)$ and $5=(>75 \%$ severe root damage $)$ 


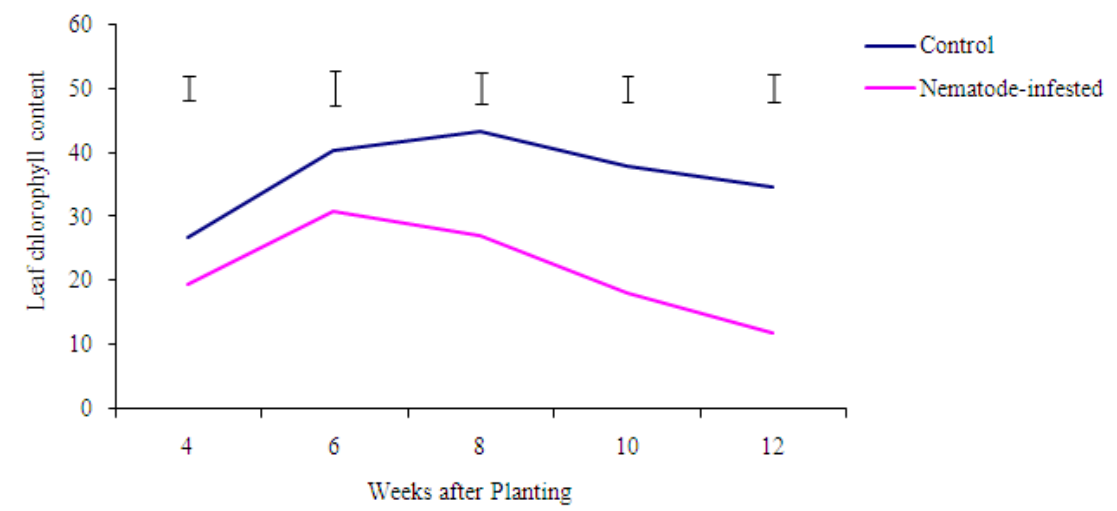

Figure 6: Effects of Heterodera sacchari on leaf chlorophyll content of NERICA rice cultivars.

LSD $_{(\mathrm{P} \leq 0.05)}$ bars are for comparing treatment means at each specific time

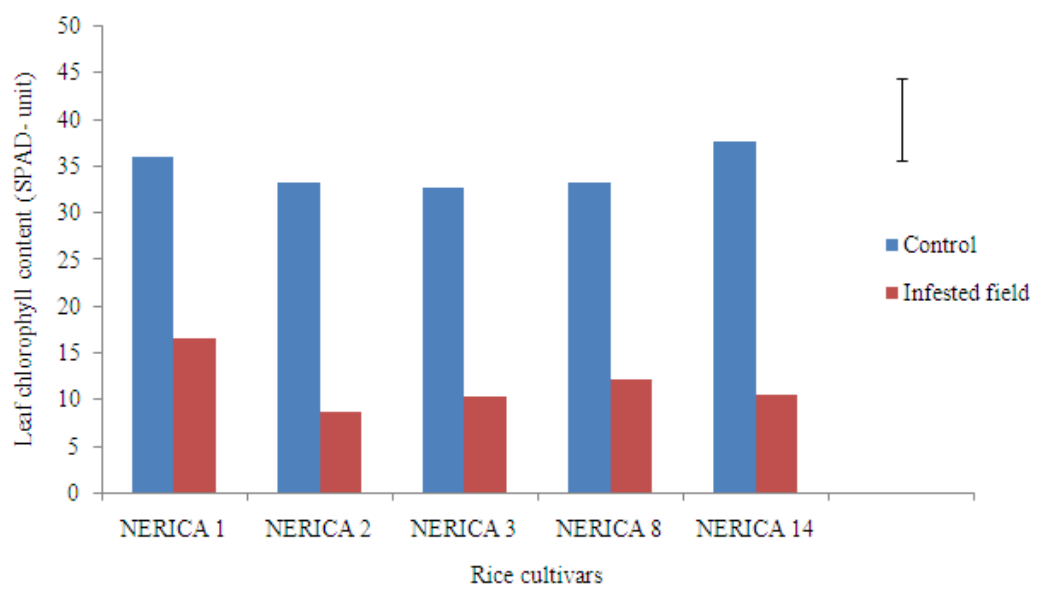

Figure 7: Effects of Heterodera sacchari on leaf chlorophyll content of five NERICA rice cultivars 12 weeks after planting. $\mathrm{LSD}_{(\mathrm{P} \leq 0.05)}$ bars for comparing treatment means across cultivars

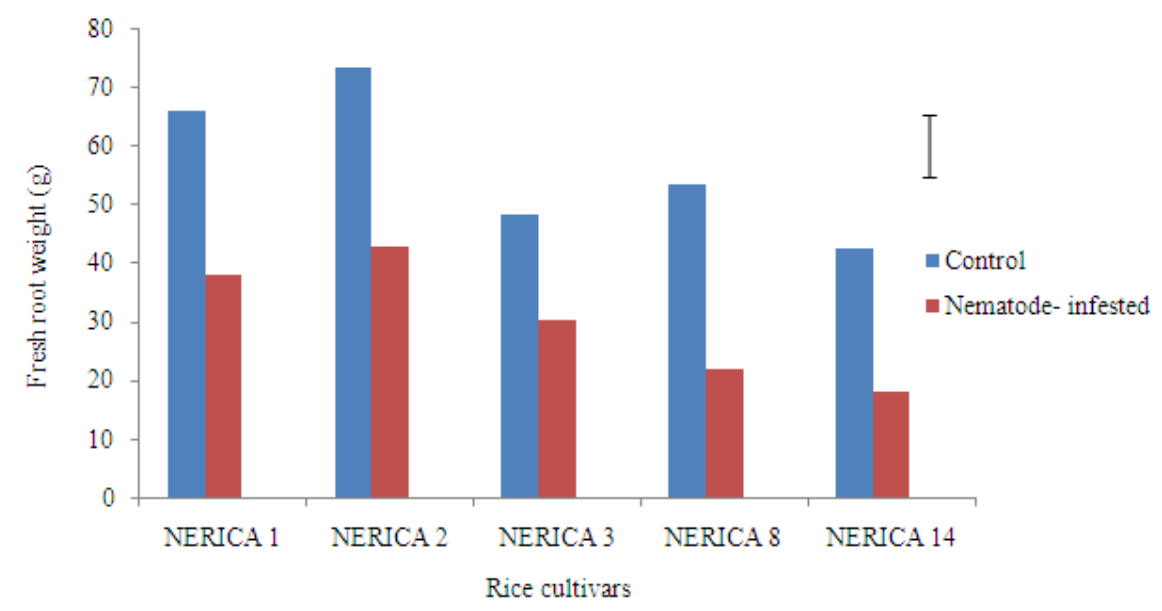

Figure 8: Effect of Heterodera sacchari population densities on root damage of some NERICA rice cultivars. LSD $(\mathbf{P} \leq 0.05)$ bars for comparing treatment means across cultivars. Root damage where; $1=$ clean, $2=(1-25 \%$ slight damage $), 3=(26-50 \%$ mild damage $), 4=(51-74 \%$ moderate root damage $)$ and $5=(>75 \%$ severe root damage $)$ 


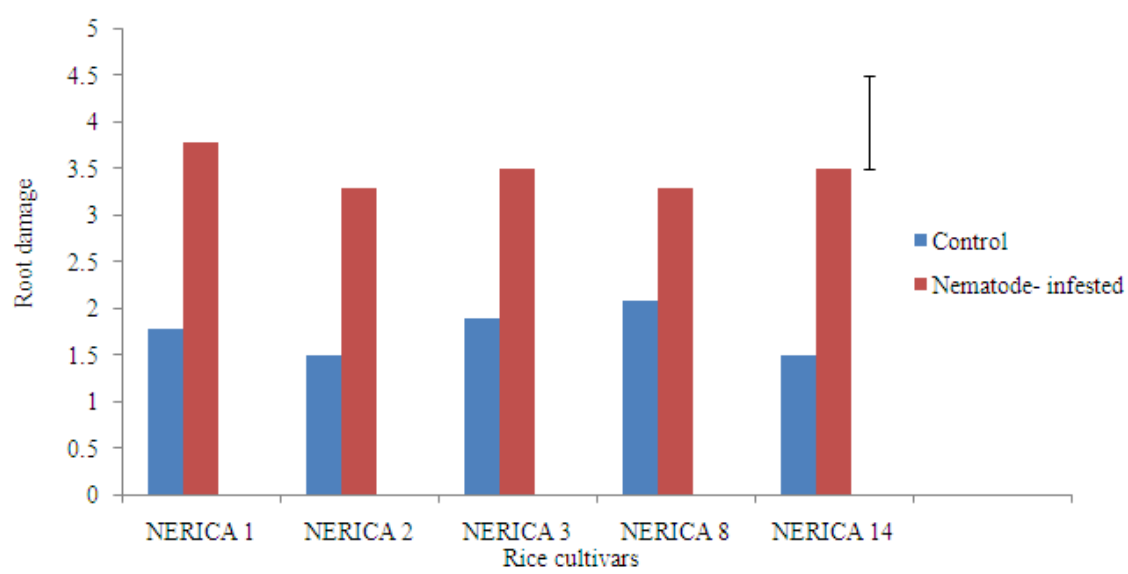

Figure 9: Effect of Heterodera sacchari population densities on root damage of some NERICA rice cultivars. LSD ${ }_{(\mathrm{P} \leq 0.05)}$ bars for comparing treatment means across cultivars. Root damage where; $1=$ clean, $2=(1-25 \%$ slight damage $), 3=(26-50 \%$ mild damage $), 4=(51-74 \%$ moderate root damage $)$ and $5=(>75 \%$ severe root damage $)$

Table 1: Reproduction of Heterodera sacchari at different population densities on five NERICA rice cultivars

\begin{tabular}{lllll}
\hline Cultivar & Treatment & Total J2 in pot & $\begin{array}{l}\text { Number of cysts } \\
\text { in pot }\end{array}$ & $\begin{array}{l}\text { Number of } \\
\text { nematode/ cyst }\end{array}$ \\
\hline NERICA 1 & Control & 0.0 & 0.0 & 0.0 \\
& 2500 eggs \& J2 & 12450.0 & 7809.3 & 287.8 \\
& 5000 eggs \& J2 & 17670.0 & 8656.5 & 286.5 \\
& 10000 eggs \& J2 & 27215.0 & 13241.3 & 308.0 \\
NERICA 2 & Control & 0.0 & 0.0 & 0.0 \\
& 2500 eggs \& J2 & 22725.0 & 3215.0 & 235.0 \\
& 5000 eggs \& J2 & 29075.0 & 3997.5 & 218.0 \\
& 10000 eggs \& J2 & 35925.0 & 4840.0 & 248.8 \\
NERICA 3 & Control & 0.0 & 0.0 & 0.0 \\
& 2500 eggs \& J2 & 7605.0 & 4621.5 & 318.5 \\
& 5000 eggs \& J2 & 9825.0 & 4867.5 & 268.8 \\
& 10000 eggs \& J2 & 10765.0 & 6772.8 & 253.5 \\
NERICA 8 & Control & 0.0 & 0.0 & 0.0 \\
& 2500 eggs \& J2 & 11860.0 & 3799.8 & 118.5 \\
& 5000 eggs \& J2 & 21755.0 & 3836.8 & 141.8 \\
NERICA14 & 10000 eggs \& J2 & 23115.0 & 4928.8 & 132.3 \\
& Control & 0.0 & 0.0 & 0.0 \\
& 2500 eggs \& J2 & 7650.0 & 7469.3 & 275.3 \\
& 5000 eggs \& J2 & 18032.5 & 7655.0 & 207.0 \\
LSD (P $\leq 0.05)$ & 10000 eggs \& J2 & 9285.0 & 13638.3 & 235.5 \\
\hline
\end{tabular}

$\mathrm{J} 2$ = second-stage juvenile, analysis of nematode data undertaken on $\log _{10}(\mathrm{X}+1)$ transformed; backtransformed means presented.

Table 2: Reproduction of Heterodera sacchari on five NERICA rice cultivars

\begin{tabular}{lllll}
\hline Cultivar & Treatment & $\begin{array}{l}\text { J2 in 250 ml soil + } \\
\text { root }\end{array}$ & $\begin{array}{l}\text { Cysts in 250 ml } \\
\text { soil + root }\end{array}$ & $\begin{array}{l}\text { Number } \\
\text { nematodes/ cyst }\end{array}$ \\
\hline NERICA 1 & Control & 1000.0 & 150.0 & 308.0 \\
& Nematode-infested & 3750.0 & 800.0 & 369.0 \\
NERICA 2 & Control & 1075.0 & 375.0 & 331.8 \\
& Nematode-infested & 2275.0 & 825.0 & 379.0 \\
NERICA 3 & Control & 1425.0 & 225.0 & 266.3 \\
& Nematode-infested & 3725.0 & 950.0 & 320.5 \\
NERICA 8 & Control & 725.0 & 225.0 & 197.3 \\
& Nematode-infested & 1575.0 & 525.0 & 247.5 \\
NERICA 14 & Control & 1075.0 & 500.0 & 257.0 \\
& Nematode-infested & 3075.0 & 1000.0 & 399.0 \\
LSD $($ P $\leq 0.05)$ & & 912.0 & 291.8 & 195.3 \\
\hline
\end{tabular}

$\mathrm{J} 2$ = second-stage juvenile, analysis of data undertaken on $\log _{10}(\mathrm{X}+1)$ transformed; back-transformed means presented. 